\title{
Towards sustainable business models from healthcare technology research
}

\section{Maurice Mulvenna* and Jonathan Wallace}

TRAIL Living Lab,

School of Computing and Mathematics,

Faculty of Computing and Engineering,

University of Ulster,

Shore Road, Newtownabbey, BT41 3HE, UK

E-mail: md.mulvenna@ulster.ac.uk

E-mail: jg.wallace@ulster.ac.uk

*Corresponding author

\section{George Moore}

School of Computing and Mathematics,

Faculty of Computing and Engineering,

University of Ulster,

Shore Road, Newtownabbey, BT41 3HE, UK

E-mail: g.moore@ulster.ac.uk

\section{Suzanne Martin}

TRAIL Living Lab,

Health and Rehabilitation Sciences Research Institute,

School of Health Sciences,

Faculty of Life and Health Sciences,

University of Ulster, Shore Road,

Newtownabbey, BT41 3HE, UK

E-mail: s.martin@ulster.ac.uk

\section{Brendan Galbraith}

TRAIL Living Lab, Department of Management, Ulster Business School, University of Ulster, Shore Road, Newtownabbey, BT41 3HE, UK

E-mail: b.galbraith@ulster.ac.uk

\section{Timber Haaker and Ferial Moelaert}

Telematica Instituut,

Brouwerijstraat 1,

Enschede, 7523 XC, The Netherlands

E-mail: timber.haaker@telin.nl

E-mail: ferial.moelaert@telin.nl 


\title{
Maria Jansson
}

Umeå University,

Umeå, 90187, Sweden

E-mail: Maria.Jansson@informatik.umu.se

\section{Birgitta Bergvall-Kåreborn}

Luleå University of Technology,

Luleå, 971 87, Sweden

E-mail: birgitta.bergvall-kareborn@1tu.se

\section{Ricardo Castellot}

Telefonica, Parque Tecnológico de Boecillo,

Boecillo, Valladolid, 47151, Spain

E-mail: rcl@tid.es

\section{Anita Melander-Wikman and Johan E. Bengtsson}

Centre for Distance-Spanning Healthcare,

Luleå University of Technology,

SE-971 87 Luleå, Sweden

E-mail: anita.melander-wikman@ltu.se

E-mail: johan.e.bengtsson@1tu.se

\section{Lennart Isaksson}

Intelliwork AB, Häggvägen 16, 95441 Södra Sunderbyn, Sweden

E-mail: lennart.isaksson@intelliwork.se

\section{Chris Nugent}

Computer Science Research Institute,

School of Computing and Mathematics,

Faculty of Computing and Engineering, University of Ulster,

Shore Road, Newtownabbey, BT41 3HE, UK

E-mail: cd.nugent@ulster.ac.uk

\begin{abstract}
As demographic ageing impacts across the world, health and welfare organisations are seeking new paradigms of care that address people's needs as well as being inherently more scalable than the incumbent processes and services. The aim of this paper is to describe the current situation in Europe with information on service provision, before signposting some possible new ways to develop sustainable business models that support care models. The paper uses a case study approach to examine the issues in the introduction of such business models, from a perspective of the translation of research proof of
\end{abstract}


concepts into business services and from the perspective of developing innovations from research that address unmet or poorly considered needs of user. The paper shows how several innovative European projects are anticipating the need for service change and are designing their research outcomes to match the needs of service commissioners more fully. The conclusion discusses several different approaches before drawing together strands of the work and providing tentative recommendations on the way forward to develop new inclusive technology-enhanced services in health and social care.

Keywords: inclusion; information and communications technology; ICT; health and welfare services; business models.

Reference to this paper should be made as follows: Mulvenna, M., Wallace, J., Moore, G., Martin, S., Galbraith, B., Haaker, T., Moelaert, F., Jansson, M., Bergvall-Kåreborn, B., Castellot, R., Melander-Wikman, A., Bengtsson, J.E., Isaksson, L. and Nugent, C. (2010) 'Towards sustainable business models from healthcare technology research', Int. J. Computers in Healthcare, Vol. 1, No. 1 , pp.20-34.

Biographical notes: Maurice Mulvenna is a Professor of Computer Science at the TRAIL Laboratory in the University of Ulster. His research focuses on pervasive computing in the areas of health and social care that can be met by translational innovation and research activities.

Jonathan Wallace is a Senior Lecturer and the Director of Knowledge and Technology Transfer for the Faculty of Computing and Engineering at the University of Ulster. His research areas include human computer interfaces, healthcare and e-Inclusion.

George Moore is a Lecturer in Computer Science and a subject expert in multimedia in the School of Computing and Mathematics, University of Ulster, Northern Ireland. His research focuses on multimedia systems across a range of areas including independent living, mobile computing and 3D technologies.

Suzanne Martin is a Lecturer in Occupational Therapy in the School of Health Sciences at the University of Ulster, Northern Ireland. Her research focuses on the integration of electronic assistive technology to support the delivery of person centred health and social care services.

Brendan Galbraith is a Lecturer in Human Resource Management in the School of Business Organisation and Management at the University of Ulster. His research focuses on innovation modelling, performance management and measurement systems for open innovation and innovation modelling for healthcare.

Timber Haaker is a Researcher at the Dutch Novay Institute in the Networked Business group. His research focuses on service innovation management, business models, service bundling and impact assessment of ICT enabled services in healthcare.

Ferial Moelaert El-Hadidy is a Senior Scientific Researcher at the Novay Institute. The key emphases in her multidisciplinary background are remote collaboration, situational aware services, ICT solutions and platforms, healthcare and multimedia. She has a particular interest in the boundary between wellness and healthcare. 


\begin{abstract}
Maria Jansson is a Researcher at Umeå University. She obtained her PhD in Social Informatics from Luleå University of Technology, Sweden. Her research focuses on user participation and user-driven design in home- and healthcare settings. She is a Researcher at Centre for Distance-spanning Healthcare at Luleå University of Technology, Sweden. Her research interests include aspects of communication in homecare and the role of technology in homecare.
\end{abstract}

Birgitta Bergvall-Kåreborn is a Professor of Social Informatics at Luleå University of Technology, Sweden and part of the Botnia Living Lab hosted by the University. Her research focuses on user-driven design and distributed user participation in both professional and private contexts.

Ricardo Castellot Lou works as a Research Engineer for Telefonica I+D. His research focuses on tele-assistance and social services development for disabled persons. He is currently coordinating a European project to help people with dementia in their daily activities and participates in other similar e-Inclusion projects.

Anita Melander Wikman holds an MSc, a FilLic in Physiotherapy and a PhD from Luleå University of Technology. Her research interests lies within the field of the empowerment of elderly people and rehabilitation.

Johan E. Bengtsson is a Senior Project Manager at Centre for Distance-spanning Healthcare at Luleå University of Technology, Sweden. He is also the Chairman of the Luleå IT business council representing 2,000 employees. His research and innovation activities focus on mobile e-Inclusion and ambient assisted living, based on cross-disciplinary international research.

Lennart Isaksson is the Director of Intelliwork AB in Sweden. His areas of interest include healthcare and mobile inclusive healthcare services.

Chris Nugent is a Professor of Biomedical Engineering at the University of Ulster. His research addresses the themes of technologies to support independent living, medical decision support systems specifically in the domain of computerised electrocardiology and the development of internet-based healthcare models. He has published extensively in these areas with the work spanning theoretical, clinical and biomedical engineering domains.

\title{
1 Introduction
}

As the effects of demographic ageing impact on the health and welfare service organisations across the world, healthcare service providers are under pressure to offer higher volumes and quality of service, often while budgets are reduced. Information and communications technology (ICT) offers the potential for innovative technology enriched services to meet demands arising from demographic ageing. Emerging health and care models therefore can help people to age in place, supported by informal carers and family within the context of their local community. Technology innovation is multifaceted impacting on device development and capacity and communication networks. Application within healthcare is not only feasible but also a more affordable and therefore viable option. These pervasive healthcare innovations may focus on the individual or may also be composed of a combination of technologies set in the context 
of new service models, perhaps developed by partnerships of companies. Health and social care organisations are responding to the drivers for change, but often have difficulties in evolving services or commissioning new services that utilise pervasive healthcare. Innovation, by definition, is new, often radically impacting on products, processes and services. Importantly the scalability of the innovation or the partnership supporting the innovation in the market is also often unknown.

Health and Welfare Organisations (HWO) and associated health and social care service providers have historically exploited ICT to support elderly people at home. Europe is experiencing the emergence of innovative and dynamic service models that utilise ICT to support the aging in place of the older person in community settings. Community care services are expanding, while consolidation of the social model of disability and a greater understanding of the biopsychosocial model is evolving. An increasing awareness of the relevance of the International Classification of Functioning Disability and Health (WHO, 2001) and a growing recognition of user empowerment is evident within society.

The pace of change is gaining momentum and services traditionally provided within the acute and tertiary sectors are now feasible in the community. In parallel, non-traditional organisational partnerships are emerging which facilitate community service provision in a format that challenges previously established norms. Often a mixed economy of service input is utilised to support disabled and elderly people at home; for example ICT, care packages and environmental adaptation. Service providers and service users are interested in understanding how ICT integrated into social care can move towards sustainable, viable mainstreamed services beyond pilot projects.

Some $30 \%$ of the European population will be aged over 60 by 2020, with, for example in Ireland, approximately 100,000 more older people living alone on the island of Ireland than recorded in 2004. Europe, like Ireland will experience increased dependency ratios in the future. While the population in Ireland is relatively young, birth rates are declining, from around $21.5 \%$ per 1,000 of population in the period $1950-1980$ to around $14.8 \%$ in 2005 (EEPC, 2003). Old-age dependency ratios in both the UK and Ireland are projected to increase dramatically (ICSO, 2007). The old-age dependency ratio is projected to double from an average of 18.5 in 2000 to 40 in 2050, meaning a change from around four to two persons of working age for every ageing person. While the provision of healthcare in the UK and Ireland is based on different structures, the direct implication of higher dependency ratios in each country and more widely in Europe is that the government must maximise its efficiency in terms of expenditure, if taxes are to remain at a reasonable level.

This demographical change will pose increased problems for health and social care systems. For ageing people, this issue may be exacerbated as they may reside in remote rural areas some distance from larger city-based specialist health services. The challenge is to change the type of care provision for increasing numbers of ageing people in both rural and urban areas allowing health services to free hospital beds more quickly, resulting in decreased overall costs to health and social service providers.

Evidence suggests that older people wish to remain living in their own homes, and that institutional care is costly (WHO, 2006). However, it has proven difficult to quantify the economic benefits (Kornowski et al., 1995) or not (Hughes et al., 1997), of home-based care versus hospital care or indeed the functional advantage gained by the individual (Ennis et al., 2003). A recent literature review and meta-analysis by Beswick et al. (2008) has stated that complex community-based interventions are associated with a 
reduction in nursing home admissions, reduced hospital admissions and a reduction in the occurrence of falls. Beswick also found that improved physical function was associated with complex interventions. Whilst this work doesn't focus on technology per se it is relevant and contributes to the evidence base supporting evolving service provision.

Delivering services to individuals in their own home can enable people to maintain their independence. It is where successful service delivery is more likely to be most cost-effective but it also brings new challenges. Helping those with chronic diseases, for example, COPD, diabetes and Alzheimer's to live independently at home will require the increased and sustained application of ICT. The following section discusses current service provision and articulates the need for the service model to evolve.

\section{Reflections on service provision}

Technology enriched healthcare can be considered as a complex intervention by the very nature of the multitude and variety of the components within the services. The emerging applications are diverse as evidenced by the wide range of solutions available. Ambiguity exists around how academics, service providers and service users categorise or classify the integration and use of technology within healthcare. Sometimes a descriptor of the created environment is used; for example, a 'Smart Home', though this is not a homogenous term and on comparison the technologies within studies may vary quite dramatically.

Heterogeneity can include the target population of citizens, the technologies integrated as an intervention and also the context of use. For example, one scenario may investigate the use of smart alarms with older people who have a diagnosis of dementia and are living alone (Doughty and Mills, 2002), whilst a second might consider the use of the 'ubiquitous home' to support adults with dementia in a supported housing scheme (Morris and Lundell, 2003). In some instances, a service descriptor is applied; for example 'telecare' or 'telehealthcare' to support a particular population of disabled people.

The Medical Research Council (2000) (UK) states that complex interventions "whether therapeutic or preventative, comprise a number of separate elements which seem essential to the proper functioning of the intervention although the 'active ingredient' of the interventions that is effective is difficult to specify".

In parallel to the complexity of the intervention, concurrent systems complexity may be present. Johnson (2001) proposed the following principle that although there are different types of complex systems generally: 'simple agents following simple rules generate amazingly complex structures. In most service scenarios, intrinsic organisational complexity is integral to the design, development and implementation of services'. Both aspects of complexity need to be understood to develop and replicate meaningful business models.

\section{Opportunities for change}

Aside from the strong arguments for change provided by the effects of demographic ageing on Europe, there are a number of other important drivers for change. One of these is the move toward viable and open innovation models, which is in line with European 
and US emerging business innovation best practice (Chesbrough, 2003). Embedding innovation in healthcare provision can help to drive modernisation of the health and welfare organisations in Europe and provide best practice exemplars to build confidence within healthcare staff teams (Galbraith et al, 2008). It is now widely known that champions of open innovation in the USA such as IBM and Procter and Gamble helped to catapult growing worldwide interest in this apparently new paradigm. Many different kinds of initiatives fall under the rubric of open innovation including the open source phenomenon in the software sector. Further, empirical studies have demonstrated the benefits of introducing users into the innovation process (von Hippel, 1986) resulting in instructive lead user methods and innovation toolkits (von Hippel and Katz, 2002). However, for all of these successes there still remain many gaps in our understanding of this area. For example, the IBM and Proctor and Gamble successes occurred in US markets where consumer power and market competitiveness is high; this certainly forces companies to be as creative as possible, including finding new ways through open innovation (Chesbrough, 2003). How can this success be replicated in less developed markets? Or, indeed, how can it be replicated in the current climate of weak EU high-tech performance, innovation and cooperation [European Commission (EU), 2007]? Also, how can the promising user innovation benefits that were largely carried out in sectors such as customised goods, leisure and electronics transgress to other high-tech sectors, such as healthcare? And, how appropriate is the lead user method and user-driven innovation toolkits, for the area of healthcare?

It is widely reported that successful innovation is about the effective management of the flows of knowledge and activity across complex networks (Lesser et al., 2000). Indeed, the breadth and complexity of the next generation of healthcare services being envisaged in terms of the stakeholders, technologies, objectives and disciplines involved, increases heterogeneity. It also raises challenges for interdisciplinary working and the translation of research to policy and practice. Maximising the potential of next-generation healthcare requires the involvement of a wider constituency of disciplinary experts, including social scientists, management (in addition to product design, healthcare and computing) (Pagliari, 2007). Empirical research has shown that the health sector has been particularly prone to product development problems including unanticipated technical, human or organisational issues (Southon et al., 1999). Moreover, design flaws that affect the ease of use and reliability of systems and may even be dangerous, creating ill-feeling and reducing clinicians' willingness to use emerging systems, software and hardware in practice (Dumay and Feriks, 2004). Even seemingly minor problems with usability or conceptual fit can destabilise the implementation of otherwise highly engineered and valid technologies (Pagliari, 2007). It is argued that to treat these problems requires open, validated user-centred methodologies and truly interdisciplinary collaboration from the beginning of the innovation process and right through to successful implementation.

\section{Case study: MH@A}

The MyHealth@Age (MH@A) project focuses on the development of new and improved products and services based on the requirements of older people and their circle of family and friends, informal carers and professional carers. The aim of MH@A is to offer the ageing population in the urban and rural areas of Northern Europe improved health, safety and well-being through the use of new services and new mobile ICT products. This 
is important since the number of elderly people is increasing rapidly, especially in the peripheral regions. Since the HWOs have limited financial resources, it is not possible to provide good quality healthcare and welfare to these people without improved work methods and utilisation of appropriate ICT equipment and applications.

The change in service delivery to accommodate the demographic and rural changes has large-scale implications for the redevelopment of healthcare infrastructures, their service provision and associated research. This will result in shifting the allocation of resources from tertiary care institutions towards the preventative management at the primary care level, as well as delivering services to individuals in their own home where they are likely to be most cost-effective as they enable ageing people to remain in their own rural homes maintaining their perception of independence. Many elderly people feel unsafe outside their homes, which limits their social contacts and physical activities. MH@A is designed to provide products and services making it possible for elderly people to feel safer and live a more active and healthy life.

The products and services focus on mobile safety alarms, prescribed self-treatment and social networks, identified as important by end-users in earlier projects. They will be developed and evaluated through field trials in close cooperation between elderly people, HWO staff, ICT companies and universities in Sweden, Norway and Northern Ireland. Through dialogues with HWO decision-makers, elderly people and market and sale partners, business models will be developed making it possible to offer the products and services in wider markets after the project.

The European Living Lab innovation model (ENOLL, 2007) is guiding the project methodology for MH@A. A Living Lab is a collaboration of public-private-civic partnerships in which stakeholders co-create new products, services, businesses and technologies in real life environments and virtual networks in multi-contextual spheres (Corelabs, 2006). This approach is multifaceted, in that, it facilitates open and continuous multi-stakeholder and multidisciplinary collaboration that originates from, and is validated by, end-user needs. It is beneficial in several ways:

1 it will synergise MH@A by leveraging the trans-national knowledge (user, business, academic and healthcare etc) in the three regions

2 iterative feedback from the market, user and technical perspectives throughout the process improves the likelihood of commercially attractive new products and services

3 studying end user needs and validating subsequent concepts, products and services with the end user in a natural and real-life setting (rather than in a controlled unnatural setting) negates the loss of some contextual complexity or slightly biased or artificial user behaviour.

This iterative process will add value to the design and development of new products and services that are driven by end users and, effectively balance user, technology and market needs.

\subsection{Market preparation}

Participatory design and participatory action research will be used to identify the end-user needs. The end-user needs are specified and validated in a three-stage co-creative design process. The design process is iterated between the 'quad-helix' of partners including: 
1 the community of end-users (elderly, healthcare professionals)

2 the business enterprises and HWOs

3 health and welfare departments

4 the multidisciplinary academic researchers.

This iterative quad-helix approach is a measured and comprehensive collaboration that serves several important functions. Namely: the convergence of knowledge perspectives over the three stages provides multidisciplinary balance; early and regular feedback from the market (HWOs and business enterprises) helps to act as a compass to steer the project on a commercial path; HWOs and academics contribute to the overall quality assurance of the project including due diligence issues, ethical awareness and rigorous and methodical feedback; and real-life contextual co-creative design with the user community (elderly and HWOs) fully informs the diagnosis as well as the solution. In short, MH@A will employ a comprehensive methodology that will create a balance between user needs, technology and the market.

Several new applications will be developed, evaluated and enhanced. Examples are fall sensor alarm with assistance support suitable both for alarm centres and for friends and relatives, prescribed self-treatment that makes it possible for HWO to offer supervised quality assured self-medication avoiding the need for own staff to perform the medication for elderly people that can manage this by themselves, enhanced social networks that will improve isolated elderly peoples social life. These are examples of applications that will be developed and evaluated. The new products and applications will make it possible for HWO to provide new services to elderly people. The new products and services will also utilise the HWO staff more efficiently making it possible for HWO to manage the increased demand for healthcare and welfare services due to the rapidly increasing number of elderly people.

\section{Case study: COGKNOW}

The aim of COGKNOW (2006) and Meiland et al. (2007) was to achieve a breakthrough with research that addresses the needs of those with dementia, particularly those living in the community with mild dementia in Europe - literally helping these people navigate through their day. This entails cognitive reinforcement in the four main areas of helping people to remember, helping to maintain social contact, helping with performing daily life and recreational activities, and providing enhanced feelings of safety. Dementia is a progressive, chronic disease affecting $5 \%$ of all persons above 65 and over $40 \%$ of people over the age of 90. In Europe by 2050, it is estimated that one-third of Europe's population will be over 60 . The number of 'oldest old' aged $80+$ is expected to grow by $180 \%$ (Eurostat, 2002). For example, in 1951, there were 300 people aged 100 and over in the UK. By the year 2031, it is estimated that this figure could boom to 36,000 (BBC, 2007). Life expectancy has been rising on average by 2.5 years per decade in Europe. There are 5.5 million cases of Alzheimer's disease in Europe and more new cases per year. 


\subsection{COGKNOW state of the art}

The COGKNOW analysis of the state of the art found that previous research has delivered devices and services which have had mixed or little success when applied to actual living conditions among ageing people with dementia (Lauriks et al., 2007). However, they have proven useful in highlighting where gaps in service and autonomy may be filled. The COGKNOW advances on the state of the art are focused on addressing these gaps and on delivering a service and technology that makes a difference in actual living conditions. The analysis of the state of the art of ICT solutions for dementia sufferers showed that various types of services and several products are available for all the most frequently mentioned unmet needs. In the current market, there are from simple products such as automatic pill dispensers or telephones with the photos of the persons frequently called, which contribute to the support for memory and social contacts, to more complex and complete GPS tracking devices that also assist in locating people with dementia when they happen to wander off. The beneficial effects of computer systems have been observed on orientation, feelings of anxiety and independency in patients suffering from Alzheimer's disease. Besides this, implementing monitoring technologies and detection devices or alarm systems inside and outside the home of elderly persons is potentially useful to enhance (perceived) safety and security of the person suffering from dementia as well as carers. New technologies have also a remarkable role in assistive cares. Internet-based applications designed to provide carers with clinical, decision-making and emotional support, were evaluated in field trials and the preliminary results showed the system to be beneficial both to carers and people with dementia (Lauriks et al., 2007). Nonetheless, despite all these services, products and technologies available to enhance and improve Alzheimer patients' quality of life, there is no system in the current market capable of offering help and solutions that cover the four main need areas previously mentioned. COGKNOW offer the potential to be a valuable system, which implements a wide range of services that not only will help people with dementia to face up their main needs, but also makes possible they lead a normal life.

\subsection{Market preparation}

Getting healthcare innovations from the pilot state to actual innovations in the market is notoriously difficult, especially as the technical components (hardware and software) must marry with existing or modified services that add value to the healthcare provider. In addition, there must be significant value-add to the circle of carers, both informal and formal and, finally, for the person with dementia, it must work. From a purely financial perspective, the proposed services supported by new technology as envisaged in COGKNOW must make financial sense. In COGKNOW, preliminary assessments have been made of the business implications of the increasing needs of people with dementia for different territories in Europe.

Significantly, as a European collaboration, the COGKNOW solution and associated service offering must provide integration routes for a broad and heterogeneous range of countries and regions across the community. At this stage, the project seeks to identify viable COGKNOW business opportunities, researching what a viable business model for these business opportunities could look like; and seeking to identify positive business factors that can be fed back into the development of COGKNOW services. 
There are significant areas of interest to the consortium in terms of the shaping of the COGKNOW business model. For example, defining what constitutes a viable business model for the service bundle of the four service areas to be developed, defining the core service or value of the COGKNOW bundle, as well as learning from business models for the provision and dissemination of other comparable ICT services, or service bundles, for ageing people (with dementia) that are already on the market. There needs to be an investigation into the roles needed to deliver the COGKNOW services, the actors involved and the identification of the most viable business configurations. The project must also examine the critical design factors, the key differentiators that mark the COGKNOW service (bundles) apart from the alternatives in the market. Most importantly, the consortium must identify viable routes to introduce the COGKNOW services into the market.

The consortium has selected the STOF model and method for designing successful business concepts upon which the COGKNOW business evaluation will be based. The STOF model uses four interrelated components or domains that together define the business model as defined by Bouwman et al. (2008):

- $\quad$ service domain: a description of the service offering, its value proposition (added value of the service offering) and the market segment at which the offering is targeted

- technology domain: a description of the technical functionality required to realise the service offering

- $\quad$ organisation domain: a description of the structure of the multi-actor value network required to create and provision the service offering, and to describe the focal firm's position within this value network

- finance domain: a description of the way a value network intends to generate benefits and/or revenues from a particular service offering and of the way risks, investments and revenues are divided across the different actors in a value network.

There is no single recipe for developing successful business models. But it is possible to identify critical design factors, which should be taken into account if the COGKNOW concept business model is meant to be successful at all (Bouwman et al., 2008). These critical design issues may provide business criteria for the further development of the COGKNOW services (UK Statistics, 2007).

\section{Discussion and conclusions}

Developing inclusive telehealth and telecare solutions for older people is complex. Input from a range of sectors is often required, i.e., statutory bodies for health, housing associations, voluntary sector providers of care, and yet it is critical that the older person and their family experience a coordinated streamlined robust service.

There is also an important aspect to the use of new technologies in the market place, based on legislation and regulations. The European Union plays a very important role in the regulatory framework for pharmaceuticals and medical technology. Public health and patient safety are two key aspects of the way that these products are regulated and used. In addition, competitiveness and innovation are also important elements. Balancing cost 
with availability of innovative products remains an important issue. However, surprisingly, there are major differences in the market structure, assistive technology delivery process and funding between all the member states which means a lack of market transparency and efficiency partly due to the complexity of the social regulatory environments. This is a major issue to be addressed by the EU and its recommendations for action are coordination at EU level to share methodologies and results of health technology assessments to increase the market transparency and facilitate the exchange of good practices; and dialogue between stakeholders and regulators to address outstanding issues in assistive technologies and medical technology.

The case examples discussed in this paper show how (parts of) the open innovation paradigm can be implemented in research projects, notably the involvement of users and (business) stakeholders right from the start. However, viable business models for the applications discussed in this paper may go beyond the traditional borders of healthcare and include services for healthy persons that address well-being and prevention. In research projects, in which the technological innovation is the main initial driver, the created mock-ups and prototypes have a tendency to demonstrate possibilities rather than addressing customer needs. Often from a user and business point of view the less technologically advanced services provide for the most viable innovations.

A big issue in this process is to determine a focal actor, i.e., an actor leading and managing the innovation. Interests may conflict and finding a viable way to divide investments, costs and revenues over the partners and stakeholders is often difficult, not in the least due to the sometime corrupting effects of healthcare's financial structures. Even if the medical value and cost-effectiveness of new solutions can be clearly demonstrated, this is by no means a guarantee that a viable business model can be realised. The creation of an experimental garden or living lab, in which new services as well as new business models can be tested, independent of current legislation, may provide the necessary environment to come to truly new innovations. For such experiments to succeed, they need to bind together private and public partners in conjunction with users in the community. There has been some movement towards these kinds of partnerships; notably academic-business-clinical (ABC) partnerships to promote innovative practice. However, it can be argued that these are a kind of science park 'artefact' situated near primary care facilities and do not adopt radically new processes or methods in model or service creation as supported by open innovation and living lab approaches.

Whatever methods are used to mainstream new inclusive healthcare services, it is clear that they must incorporate measures that provide meaning and value to all stakeholders in the evolving services. A unified multi-stakeholder, multivariable methodology that measures the utility of a service could provide useful. Such a method could be comprised of components from existing methodologies; for example, EuroQol (1990), which is concerned with measurement of health-related quality of life, or RATER (previously called SERVEQUAL) developed to measure service quality in healthcare as well as banking and education (Buttle, 1996).

In determining the utility of a new or adapted service that is technologically enhanced, that utility may be crudely defined as a summation of benefits less the cost of the service change. The service change cost may be comprised mainly of the technology cost, which may be amortised. The difficulty is in defining the benefits. Benefits can be calculated based upon health interventions avoided but that approach may be simplistic. 
There is the benefit to: the user or person with the need for the service, informal carers and family, formal carers, those with clinical responsibility, the service providers as well as more complex relationships to potential beneficiaries such as pharmacists.

The core of the problem with the uptake of inclusive healthcare services in Europe and beyond is that the benefit that the recipient of the service receives - as a financial value representing the summation of the stakeholders' benefit - must be greater than the cost of the provision of the service. Perhaps the corollary is that the opportunity is in demystifying this relationship.

\section{Acknowledgements}

The paper acknowledges the support of the Northern Periphery Programme for the MyHealth@Age project and the EU's Information Society Technologies (IST) programme under Grant 034025 for the COGKNOW project.

\section{References}

BBC (2007) 'Britain's ageing population', available at http://news.bbc.co.uk/1/hi/health/395143.stm [accessed on 6 March 2008].

Beswick, A.D., Rees, K., Dieppe, P., Ayis, S., Gooberman-Hill, R., Horwood, J. and Ebrahim, S. (2008) 'Complex interventions to improve physical function and maintain independent living in elderly people: a systematic review and meta-analysis', The Lancet, Vol. 371.

Bouwman, H., Faber, E., Haaker, T., Kijl, B. and De Reuver, M. (2008) 'Conceptualizing the STOF model', in H. Bouwman, T. Haaker and H. de Vos (Eds.): Mobile Service Innovation and Business Models, Springer Verlag, Heidelberg, Germany.

Buttle, F. (1996) 'SERVQUAL: review, critique, research agenda', European Journal of Marketing, Vol. 30, No. 1, pp.8-31.

Chesbrough, H. (2003) Open Innovation: The New Imperative for Creating and Profiting from Technology, Harvard Business School Press, Boston, MA.

COGKNOW (2006) 'Description of COGKNOW project', available at http://www.cogknow.eu [accessed on 6 March 2008].

Corelabs (2006) 'Description of CORELABS project', available at $\mathrm{http}: / /$ www.ami-communities.net/wiki/CORELABS [accessed on 6 March 2008].

Doughty, K. and Mills, P. (2002) 'Telecare technologies to manage problems of rurally isolated older people in county Durham', paper presented at Turned on to Technology - A Modern Vision for Person-Centered Care, London, England.

Dumay, A.C.M. and Feriks, G. (2004) 'Quality management issues for medical ICT', Stud. Health Technol. Inform., Vol. 103, pp.93-100.

EEPC (2003) 'European Economic Policy Committee Report: budgetary challenges posed by ageing population: the impact on public spending on education', available at http://ec.europa.eu/economy finance/epc/documents/2003/pensionmaster en.pdf [accessed on 6 March 2008].

Ennis, J.M., DeBaun, L. and Habasavich, R. (2003) 'The impact of home care services on functional outcomes of stroke patients', Abstr. Acad. Health Serv. Res. Health Policy Meet. 2000, Vol. 17, available at http://gateway.nlm.nih.gov/MeetingAbstracts/102272095.html [accessed on 6 March 2008]. 
ENOLL (2007) European Network of Living Labs, available at http://www.openlivinglabs.eu/ [accessed on 6 March 2008].

European Commission (2007) Towards a European Research Area - Science, Technology and Innovation, Key Figures 2007, available at http://cordis.europa.eu/documents/documentlibrary/97946551EN6.pdf [accessed on 6 March 2008].

EuroQol (1990) 'EuroQol - a new facility for the measurement of health related quality of life', Health Policy, Vol. 16, pp.199-208.

Eurostat (2002) Health Statistics - Key Data on Health 2002, available at http://epp.eurostat.ec.europa.eu/cache/ITY_OFFPUB/KS-08-02-002/EN/KS-08-02-002EN.PDF [accessed on 6 March 2008].

Galbraith, B., Mulvenna, M.D., McAdam, R. and Martin, S. (2008) 'Open innovation in connected health: an empirical study and research agenda', Conference on Open Innovation: Creating Products and Services through Collaboration (ISPIM-2008), Tours, France.

Hughes, S.L., Ulasevich, A., Weaver, F.M., Henderson, W., Manheim, L., Kubal, J.D. and Bonarigo, F. (1997) 'Impact of home care on hospital days: a meta analysis', Health Services Research, available at http://findarticles.com/p/articles/mi_m4149/is_n4_v32/ai_20123540 [accessed on 6 March 2008].

ICSO (2007) Statistics from the Irish Central Statistics Office, available at http://www.cso.ie/ [accessed on 6 March 2008].

Johnson, S. (2001) Emergence: The Connected Lives of Ants, Brains, Cities and Software, Touchstone, New York.

Kornowski, R., Zeeli, D., Averbuch, M., Finkelstein, A., Schwartz, D., Moshkovitz, M., Weinreb, B., Hershkovitz, R., Eyal, D., Miller, M., Levo, Y. and Pines, A. (1995) 'Intensive home-care surveillance prevents hospitalization and improves morbidity rates among elderly patients with severe congestive heart failure', American Heart Journal, April, Vol. 129, No. 4, pp.762-766.

Lauriks, S., Reinersmann, A., Roest, H., van der Meiland, F.J.M., Davies, R.J., Moelaert, F., Mulvenna, M.D., Nugent, C.D. and Dröes, R.M. (2007) 'Review of ICT-based services for identified unmet needs in people with dementia', Ageing Research Reviews, Vol. 6 No. 3, pp.223-246.

Lesser, E., Fontaine, M. and Slusher, J. (2000) Knowledge and Communities (Resources for the Knowledge-based Economy), Butterworth-Heinemann.

Medical Research Council (2000) A Framework of Development and Evaluation of RCTs for Complex Interventions to Improve Health, MRC, London.

Meiland, F.J.M., Reinersmann, A., Bergvall-Kareborn, B., Craig, D., Moelaert, F., Mulvenna, M.D., Nugent, C., Scully, T., Bengtsson, J. and Dröes, R-M. (2007) 'COGKNOW: development of an ICT device to support people with dementia', The Journal of Information Technology in Healthcare, Vol. 5, No. 5, pp.324-334.

Morris, M. and Lundell, J. (2003) Ubiquitous Computing for Cognitive Decline: Findings from Intel's Proactive Health Research Seattle, Intel Corp., WA.

Pagliari, C. (2007) 'Design and evaluation in ehealth: challenges and implications for an interdisciplinary field', Journal of Medical Internet Research, April-June, Vol. 9, No. 2.

Southon, G., Sauer, C. and Dampney, K. (1999) 'Lessons from a failed information systems initiative: issues for complex organisations', Int. J. Med. Inform., Vol. 55, No. 1, pp.33-46.

UK Statistics (2007) 'UK population to rise to $65 \mathrm{~m}$ by 2016 ', available at http://www.statistics.gov.uk/cci/nugget.asp?id=1352 [accessed on 6 March 2008].

von Hippel, E. (1986) 'Lead user: a source of novel product concepts', Management Science, Vol. 32, No. 7, pp.791-805. 
von Hippel, E. and Katz, R. (2002) 'Shifting innovation to users via toolkits', Management Science, Vol. 44, No. 5, pp.629-644.

WHO (2001) World Health Organization - International Classification of Functioning, Disability and Health, WHO, ICF, Geneva.

WHO (2006) 'What is the effectiveness of home visiting or home-based support for older people?', available at http://www.euro.who.int/Document/e83105.pdf [accessed on 6 March 2008]. 